\title{
Visualizing the cultural landscape gene of traditional settlements in China: a semiotic perspective
}

\author{
Zui Hu, ${ }^{1}{ }^{\infty}$, Josef Strobl ${ }^{3}$, Qingwen Min ${ }^{1 *}$, Min Tan $^{2}$ and Fulong Chen ${ }^{4}$
}

\begin{abstract}
China has a deep traditional culture and a long history, and is rich in traditional settlements (designated as "Famous Historic-Cultural Villages/Towns", "Chinese Traditional Villages" by Chinese Government). To help people develop these traditional settlements to achieve the great goal of Chinese National Rejuvenation, Chinese scholar put forward the Cultural Landscape Genes of Traditional Settlements (CLGTS) in 2003. Since then, CLGTS theory has been employed to solve the issues of Chinese traditional settlements, such as the identification and regionalization of cultural landscape genes in traditional settlements, and the understanding of architectural features. Although CLGTS theory has made great strides in many application fields, there is still a lack of scientific findings in exploring the symbol mechanism from a perspective of semiotics. To explore this, we firstly examined the core features of CLGTS through a dialectical perspective. We analyzed two features of CLGTS in depth. First, CLGTS is the dialectical combination of macro settlement image and micro cultural factors of traditional settlements, material appearance and inherent traditional cultural implications, overall features and local self-renewal mechanisms, qualitative and quantitative methods, superiority of cultural factors and rich cultural connotation. Second, CLGTS is famous for its nonlinearity, self-organization, and selfiteration due to various spatial shapes and complex structures. Based on the above, we first proposed the concept of Symbolization Method of CLGTS (SM-CLGTS). Then, we further explored the key features, classification methods, and corresponding representation methods of CLGTS symbols. Finally, by using Visual C\#.net program language, we developed a prototype system of the Traditional Landscape Genetic Symbol Database (TLGSD) to create and centrally manage CLGTS symbols. Test results show that TLGSD can meet the needs of constructing a CLGTS symbol database for a given region. This study is of great significance to explore and contribute to visualizing the CLGTS symbols.
\end{abstract}

Keywords: Traditional settlements, Cultural Landscape Genes of Traditional Settlements (CLGTS), Semiology, Symbolization Method of CLGTS, Traditional settlement genetic symbol database (TLGSD), Application

\section{Introduction}

The great goal of Chinese National Rejuvenation was officially put forward at the 19th National Congress of the Communist Party of China in 2017 [1]. Since then, China has paid more attention to traditional settlements than ever before, such as "Famous Historic-Cultural Villages/

\footnotetext{
*Correspondence: minqw@igsnrr.ac.cn

1 Institute of Geographic Sciences and Natural Resources Research,

Chinese Academy of Sciences, Beijing 100101, China

Full list of author information is available at the end of the article
}

Towns" and "China Traditional Villages" (designated and issued by Chinese government). Because traditional settlements are rich in excellent traditional cultural heritage, such as ancient architectural technologies, ancient art [2], planning concepts, and philosophy of man-land relationship. At present, in the past decades, many research findings on key issues have been published, such as preservation [3, 4], eco-environment [5], architecture [6] and tourism value [7], etc. To a certain extent, these studies have helped to support the social strategies of China,
Springer Open

(c) The Author(s) 2021, corrected publication 2021. Open Access This article is licensed under a Creative Commons Attribution 4.0 International License, which permits use, sharing, adaptation, distribution and reproduction in any medium or format, as long as you give appropriate credit to the original author(s) and the source, provide a link to the Creative Commons licence, and indicate if changes were made. The images or other third party material in this article are included in the article's Creative Commons licence, unless indicated otherwise in a credit line to the material. If material is not included in the article's Creative Commons licence and your intended use is not permitted by statutory regulation or exceeds the permitted use, you will need to obtain permission directly from the copyright holder. To view a copy of this licence, visit http://creativecommons.org/licenses/by/4.0/. The Creative Commons Public Domain Dedication waiver (http://creativecommons.org/publicdomain/zero/1.0/) applies to the data made available in this article, unless otherwise stated in a credit line to the data. 
such as "Rural Revitalization" [8] and "New Urbanization" $[9,10]$.

However, through the existing literature, there is a lack of research on the use of semiotic principles and methods to explore the geographic characteristics of cultural landscapes of traditional settlements. This directly makes it difficult to grasp the holistic features of traditional settlements and establish a corresponding research framework from a scientific perspective.

As we all know, language symbols play an important role in understanding the socio-cultural factors and are the basic media for communication and transmission of information. Semiotics provides a theoretical foundation for exploring social cultures [11]. For example, people can use principles of semiotics and graphic variables [12] to build smart manufacturing systems [13], and people can also use methods of semiotics to improve humancomputer interaction [14] and engineering icon design [15]. This significantly hints that people can understand the socio-cultural meanings carried by cultural factors of traditional settlements from the perspective of semiotics.

Carl O. Sauer proposed the concept of cultural landscape in 1925 [16]. Since then, people have been struggling to explore the evolutionary characteristics of regional cultures from different viewpoints, such as "sequential occupation" [17] and "Morphogenesis" [18]. And now, some scholars have elucidated the core cultural features of different settlements through combining quantitative methods and image [19]. For example, D Wang [20] established a mathematical function to determine the relationship between dwelling area, direction, and distance. However, the current researches are still unable to thoroughly address the geographical features of cultural landscapes of traditional settlements. It is of paramount significance to establish a new method to analyze the cultural features of traditional settlements from a semiotic perspective.

The evolution of history and culture shows that spatial information has strategic value to human society [21]. In fact, this has promoted the development of maps. Maps are usually considered as the third language of human beings since they can help people describe, exchange, and transmit spatial information. People have made meaningful progress in many areas of cartography, such as development and evolution of the map symbols [22] and development of map symbol standards [23]. In addition, people also made fruitful findings in cartosemiotics [24] and other fields, such as the traits of semiotic system [25], information components of and pertinent retrieval approach [26], semantic analysis methods [27], and sign production process [28]. This effectively promotes the implementation of dynamic designs of map symbols from the perspective of semiotics.
Map symbols can represent the semantic properties [27] and features of geographical objects. They can be also treated as the basic media for communicating, transmitting, exchanging, and expressing spatial information [21]. From the perspective of semiotics, map symbols are the visual symbolic system and are akin to human natural languages [29]. Because they are considered as an effective communication tool for expressing spatial information and geographical phenomena or expressing the development and evolutionary features of geographical systems.

It is well-known that map symbols can reveal the real states and core features of ancient societies and cultures through the principles and methods of cartosemiotics [24]. In essence, the features of cultural landscape of traditional settlements are a comprehensive reflection of the cultural and social features in ancient China. Map symbols therefore can help to understand the features of cultural landscape of Chinese traditional settlements.

It is important to stress that traditional settlements are the product of the development of civilization. Among them, human activities and behaviors are attached to the background of natural landscapes. In part, traditional settlements have the attributes of natural landscapes. For example, the rural landscapes including traditional rural settlements provide an important platform for integrating biological and cultural diversity to improve human well-being [30]. At the same time, traditional settlements are rich in historic and social information. Traditional settlements therefore can be treated as one type of very special geographical entities. This challenges people to examine the socio-cultural properties and historic cultural value of traditional settlements through the perspective of spatial information. So, with the support of the principles of graphic language [12] and cartosemiotics [24], we can fully explore the geographic features of traditional settlements. This is also in line with the way of human thinking and understanding.

PL Liu first proposed the concept of Cultural Landscape Genes of Traditional Settlements (CLGTS) in 2003 [31]. According to PL Liu, CLGTS is defined as the critical cultural factor that can distinguish its attached traditional settlement from the others. On the contrary, people can also identify a traditional settlement of a given region through its corresponding CLGTS. CLGTS is based on the theory of cultural gene and the analysis methods of biology and is employed to understand the core characteristics of the cultural landscapes of Chinese traditional settlements from a 
geographic perspective. To fully capture the geographic features of traditional settlements, with the support of bioinformatic and Geo-Information Tupu ${ }^{1}$ [32], CLGTS is mainly committed to determining the most outstanding cultural factors of Chinese traditional settlements and establishing a scientific framework of cultural landscape genome maps [33] (Cultural landscape genome maps mean that people employ the principles and methods of culturomics and bio-informatics to explore the nature of relationship between the cultural landscape image of traditional settlements and their corresponding CLGTS.). CLGTS is widely used to solve the issues of cultural landscapes of Chinese traditional settlements, mainly covering the identification and regionalization of cultural genes [34-36], the understanding of architectural features, and the support of the tourism development [31].

However, at present, some crucial scientific issues of CLGTS, such as physical shape, appearance, spatial structure, and expression method, have not been thoroughly explored. The root of the former issues lies in the lack of using relevant principles and methods of semiotics to explore the natural characteristics of cultural landscape genes. This work attempts to explore the Symbolization Method of CLGTS (SM-CLGTS) from the perspective of semiotics. According to the core characteristics of CLGTS, this work is devoted to exploring the key issues of CLGTS symbols, such as symbol features, classification methods, and corresponding symbolization methods. The objective of this work is to provide theoretical support for the application of CLGTS symbols. Simultaneously, this work is also to explore the application of CLGTS symbols through developing the procedure of Traditional Landscape Genetic Symbol Database (TLGSD). We hope this work can help to further frame CLGTS theory and promote the use of CLGTS in a wide range of application domains.

\section{The features of CLGTS CLGTS theory briefing}

CLGTS was first put forward by the Chinese scholar PL Liu [31]. Since then, CLGTS theory has mainly kept on exploring and capturing the cultural features of Chinese traditional settlements by connecting GIS, bioinformatic, and settlement geography. CLGTS theory is based on three ideas: integrity, graphical representation, and

\footnotetext{
${ }^{1}$ Chinese Professor Shupeng Chen first proposed the concept of Tupu in 2000. Tupu is a conceptual framework that integrates maps and GIS to the explore the geographical laws of nature or human society. Tupu uses a series of thematic maps or geographic graphs/diagrams/tables/curves organized by the relevant mathematical functions or metrics to reveal the corresponding laws.
}

cell-chain-figure [31]. And these theoretical ideas support the identification and expression of CLGTS from traditional settlements. In order to help people to understand and identify CLGTS, PL Liu [43] presented four identification rules, including inner uniqueness, exterior uniqueness, local uniqueness, as well as overall superiority [31]. According to these identification rules, $\mathrm{Z} \mathrm{Hu}$ [34] developed a set of indicators to distinguish CLGTS from many cultural factors in traditional settlements through identification methods such as element, pattern, structure, and connotation [34]. The set of indicators consists of fourteen single factors, which are divided into four classes: architectural features, cultural features, environmental features, and spatial layout features. The identification rules, methods, and corresponding indicators promote and forward the wide application of CLGTS theory together, such as establishing a CLGTS genome map for a given region [33], interpreting the spatial pattern of CLGTS at provincial level [34], determining CLGTS of traditional rice-terrace area [35], regionalizing the geographical characters of a minority area [36], etc.

\section{Scientific features of CLGTS}

CLGTS is an important method for establishing CLGTS Tupu in China [32, 36]. CLGTS Tupu means that people employ the principles and methods of Geo-Information Tupu [31] to map and address the core features of CLGTS in a given region. CLGTS Tupu is of great implications to understand the cultural features of traditional settlements of a given region from a geographic perspective. For example, we can use CLGTS Tupu to show the natural features of a certain important cultural factor of a given traditional settlement. It thus is of great significance to clarify the scientific characteristics of CLGTS. In this work, we mainly explore the scientific features of CLGTS from three aspects: dialectical features, morphometric features, and structural features.

\section{The dialectical features}

Richard Dawkins first introduced the concept of gene into the socio-cultural areas, and proposed to use it as a "meme" in 1976 [38]. E. O. Wilson presented the theory of co-evolution of human gene and socio-culture based on the genetic characteristics of human socio-cultures $[39,40]$. Geographers mainly study the features of regional cultural genes from the perspective of humanism. For example, Conzen proposed the Morphogenesis Theory in 1988 [18].

CLGTS theory has been nourished by ancient Chinese ecological thinking, plan concepts, and the philosophy of man-land relationship [41]. Since its introduction, CLGTS has developed a series of methods to identify the outstanding cultural factors in 


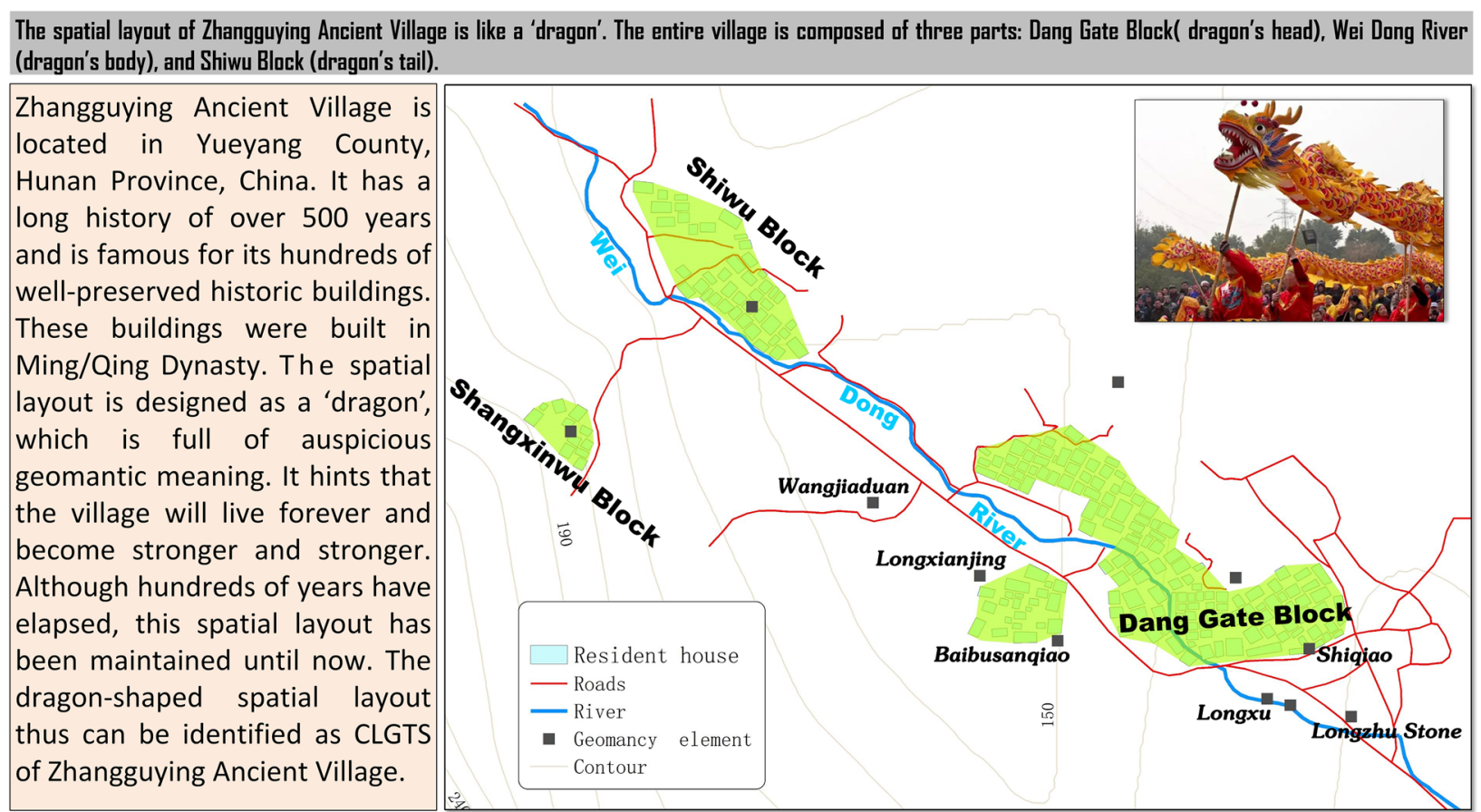

Fig. 1 The concept of CLGTS: CLGTS means the cultural factors existing in traditional settlements, which can distinguish its host settlement from other cultural landscapes. Note that CLGTS can be inherited from generation to generation and plays a decisive role in the formation of cultural landscapes. And vice versa, CLGTS can also play a decisive role in recognizing the cultural landscapes

traditional settlements, such as pattern, text, element, and structural features [33, 42]. CLGTS is of scientific significance since it provides cultural geography with the analysis methods of natural sciences to explore the features of traditional settlements. This is meaningful from the perspective of scientific philosophy.

To begin with, CLGTS is a dialectical combination of a macro image of traditional settlement landscapes and their micro cultural factors. From the conceptual scope of CLGTS, cultural landscape genes are the uniquely identifiable [43]. In practice, people mainly think about the image features of traditional settlement landscapes from a holistic perspective to distinguish different settlements with similar cultural properties. For example, only by treating the three scattered blocks as a whole (Fig. 1) can we understand the dragon-shaped layout of Zhangguying Village [32] in Hunan Province, China. The cultural landscape genes usually hidden in different traditional settlements can reflect the cultural differences of settlements in different details or at different levels. For example, Ma Tau Wall is a common architectural decoration style in traditional Chinese courtyards; however, Ma Tau Walls often have different cultural differences in different regions, which can only be distinguished by details such as shapes, arcs, and bends [44].
Furthermore, CLGTS is a dialectical combination of physical appearance features and inherent traditional cultural meanings of traditional settlement landscapes. The cultural factors of traditional settlement landscapes usually have the corresponding physical carriers. In fact, even the intangible cultural factors of traditional settlements can also reflect the key characteristics of related objects. For example, only by providing a certain space in Chinese traditional settlements can the Nuo Opera be performed, which is one kind of traditional operas originated in some rural areas in China [44]. As long as the following conditions are met, a cultural factor can be truly defined as a recognizable CLGTS: (i) it must undertake the certain special functions conferred by traditional settlements; (ii) it must occupy a specific spatial position in traditional settlements; and (iii) it must reflect some social ethics, functions, or cultural meanings contained in traditional settlements. Note that only meeting the above conditions can a CLGTS be significant when capturing the spatial image of a given traditional settlement.

In addition, CLGTS is a dialectical combination of the entire features and local self-renewal mechanisms in the inheritance process. It is well known that biological genes can maintain their own characteristics in the genetic process without fundamental changes. However, a certain 
degree of trait changes of biological genes (e.g. mutation) can also be induced or triggered by some peculiar factors. For example, tobacco smoke associated DNA adducts may cause mutations in human larynx squamous cells [45]. The same is true of CLGTS in the process of inheritance. Cultural landscape genes always try to maintain the stability of their important features or attributes. On the other hand, due to different cultural ecological environment, the cultural landscape genes will also undergo corresponding changes in the process of their spread. This implies that a certain degree of self-renewal has emerged in some details. For example, for the Hakka Tulou, although their enclosure patterns have changed from square to quasi-square and then circular, their main features are still kept, such as function, social statute, and cultural meanings [46].

Additionally, CLGTS is a dialectical combination of qualitative and quantitative analysis methods of traditional settlement landscapes. In the history of geography, qualitative methods have long been the mainstream research methods. Since the revolution of computation geography [47], quantitative methods have gradually become popular. However, in the domains of cultural geography, scholars tend to employ qualitative methods when tackling with research issues. We notice that CLGTS has organically combined qualitative and quantitative methods by introducing some bio-informatic methods. This will help to enrich the methodologies of cultural geography. For example, the exploration of CLGTS spatial patterns of Hunan Province, China mainly used qualitative methods [34]; however, the exploration of CLGTS genome maps of Hunan Province, China mainly used quantitative methods [33].

Finally, CLGTS is a dialectical combination of the superiority of core features and the cultural connotations of traditional settlement landscapes. In the traditional settlement landscapes, CLGTS is one of the most recognizable cultural factors. For example, Gulou is the grandest and the most majestic building in the Dong Minority villages/camps, and vice versa: Gulou is also the most important cultural symbol to identify the Dong Minority villages/camps. CLGTS usually contains rich cultural connotations. This means that CLGTS can reflect many important features of traditional settlements. What needs to be emphasized is that although the superiority of core features and cultural connotations are the two aspects of CLGTS, they are consistent, not opposite.

Through the above dialectical relationships, we can conclude that CLGTS is a scientific concept (Fig. 1). CLGTS is not only an objective reality but also contains profound and rich traditional cultural characteristics, such as traditional social institution, traditional ethic, traditional philosophy, traditional custom, and clans, etc.
In addition, CLGTS can not only explore the scientific features of traditional settlement landscapes from the perspective of natural science, but also generalize the cultural features of traditional settlement landscapes from the perspective of cultural geography.

\section{Morphometric features}

CLGTS has its own physical characteristics and appearances. And in the traditional settlement space, CLGTS is full of close connections, rather than isolated. For example, the Dang Gate of Zhangguying Village (situated in Yueyang County, Hunan Province, China) consists of a group of Chinese traditional courtyards [48] arranged on the same axis of symmetry, and its entire spatial layout is designed as a Chinese character “丰”.

In the process of site selection, design, and construction, many Chinese traditional settlements have emphasized the need to maintain the traditional customs and show their own characteristics. They also pay attention to creating spatial image with rich traditional cultural meanings according to different geo-environments, time, places, and landscapes [49]. In ancient China, people usually tended to create a spatial layout with rich geomancy beliefs [50] in terms of the corresponding natural environment while constructing the settlements. For example, the Longjia Courtyard Group of Heizuling Village (situated in Xingtian County, Hunan Province, China) is famous for its spatial layout of "five generations living together" (According to the meanings of traditional Chinese cultures, this spatial layout means that five generations of the same clan live in the same courtyard together and share the same hall. It hints that a large group of traditional courtyards have been built to accommodate an enormous family.). This objectively contributes to the diversity of CLGTS spatial forms. For example, $\mathrm{Z} \mathrm{Hu}$ et al. [33] pointed out that the spatial layouts of traditional settlements in Hunan Province mainly include sector and circle.

According to PL Liu et al. [51], CLGTS spatial forms mainly include square series and circular series, as well as various geomantic forms based on environmental conditions (Fig. 2). The square series includes different variations based on the square shape. For example, many spatial forms are derived from the courtyard dwellings/ Siheyuan, such as Jing/yard, Hall, and patio/Tianjing [48]. The circular series includes a couple of variations based on the circular shape, mainly including ellipse and quasicircle. For example, the spatial forms of Tulou in Fujian Province [50] mainly include circle and ellipse. To sum up, the spatial forms of Chinese traditional settlements have changed from square to circle, and then to irregular shapes [51]. 


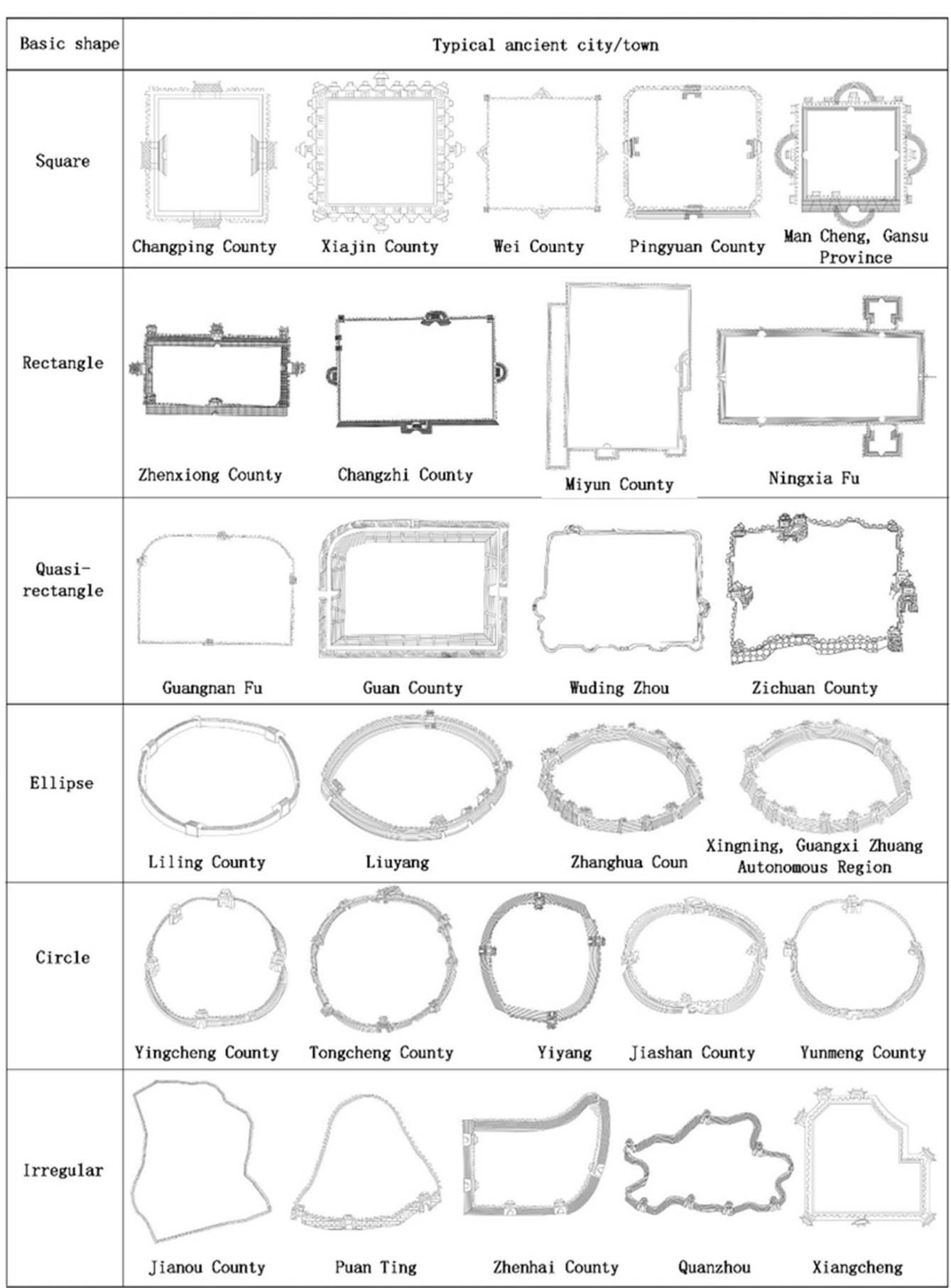

Fig. 2 Examples for spatial layouts of traditional settlements [51]

It is important to stress that, in ancient China, the northern region is the main habitat for people. In north China, the relief is low and the main landform is plain. In ancient China, people often designed and constructed regular square houses, courtyards, and settlements. Because the traditional geomancy originated thousands of years ago in ancient China highlights 'Heaven was round' and 'Earth was square', and the traditional geomancy dedicated to enhancing and maintaining the coexisting relationships between human beings and natural environments. In ancient China, people had been pursuing the harmony survival with nature. And this has 
been the main aim of geomancy from ancient to now. In history, the spatial form of house and settlements had turned into circle when people migrated from north to south due to the lack of plains in south China.

\section{Structural features}

CLGTS shows different characteristics in spatial organization and forms various spatial structures with rich traditional cultural meanings [33]. With reference to the existing research cases $[33,46,51]$, it can be found that the spatial structures of CLGTS have the characteristics of nonlinearity, self-organization, and self-iteration.

First, CLGTS is nonlinearly arranged in the traditional settlement spaces. As we all know, for physical space in nature, the linear spatial structure is a common arrangement, which can be accurately described by linear equations. The constituent elements of traditional settlements are nonlinearly arranged, which is determined by the natural geo-environment conditions in which the traditional settlements are located. The natural geo-environment is full of complexities, nonlinearities, and randomness. This makes it difficult for different constituent elements in traditional settlement spaces to form a regular linear arrangement, such as streets, and alleys.

In fact, the layout of the constituent elements of traditional settlements must be in accordance with the geospace where the settlements are located. The constituent elements of traditional settlements thus are difficult to be regularly arranged like the linear structures, because their arrangement is mainly affected by the geo-environments. At the same time, the arrangement and layout of the constituent elements of traditional settlements are also planned according to the design ideas and concepts of settlements in ancient times. To a certain extent, CLGTS can be understood as the mapping of various cultural factors in the traditional settlement space on the socio-cultural dimensions. This suggests that the cultural factors or non-material cultural factors in the traditional settlement space are also nonlinearly arranged. For example, the most ideal city in ancient China recorded in "Kao-Gong-Ji" ${ }^{2}$ is a 3-Li (an ancient length unit in China) square city; however, due to the complexity of the geoenvironments, it is difficult to construct an ideal city with ideal spatial layouts in the real world.

Second, CLGTS shows the self-organizing features in traditional settlement space. We know that the size of a settlement will expand in the process of its development as the population grows. All the constituent elements of

\footnotetext{
2 "Kao Gong Ji" is a famous ancient book in China. It originates from "Zhou $\mathrm{Li}$, which records the various specifications and manufacturing processes of handicraft industry owned by the government during the Spring and Autumn Period in China.
}

settlements gradually change from irregular to regular and from disorder to order. This is not only in accordance with the evolution law of natural systems, but also in accordance with the development process of human civilization. In fact, the constituent elements of traditional settlements are organized well and are not in a mess. Through organic planning of various constituent elements, many traditional settlements created spatial structures with special cultural significance. For example, Zhuge Ancient Village (located in Zhuji City, Zhejiang Province, China) is famous for "Eight-Diagram-StreetAlley" spatial structures [52].

In addition, the constituent elements of settlements with similar functions also tend to congregate together. Because the congregated constituent elements (e.g. shops/ stores) can ultimately share the common infrastructures of settlements and attract customers. For example, the intact Water-Street ${ }^{3}$ can still be found in the ancient towns south of the Yangtze River in China, such as Zhouzhuang Ancient Town [53], Tongli Ancient Town.

Third, CLGTS also has the characteristics of self-iteration in the traditional settlement space. Iteration is a regular self-similarity that can be accurately described by mathematics. In nature, the objective objects with iterative characterizations have precise spatial structures, such as honeycomb, tree texture, biological genes. In fact, many precise spatial structures can also be observed in CLGTS. For example, ancient buildings in traditional settlements often use patterns or textures with precise structures to decorate windows. Iteration can also be considered as a self-repair and self-development mechanism of natural systems during the evolution process. In fact, the self-iteration phenomena can also be found in the humanities and society. For example, the generation reproduction of families is a regular iterative process that can be recorded by genealogy [54].

The self-iterative features of CLGTS are similar to biological genes. Because the cultural connotation, appearance characteristics, and physical carriers of CLGTS are completely replicated and spread during the inheritance process. For example, in the field investigations in Jingshan Ancient Village (located in Rucheng County, Hunan Province, China), $\mathrm{Z} \mathrm{Hu}$ et al. [55] found that the techniques and experience of making Hong-MengLiang, ${ }^{4}$ which originated hundreds of years ago, were completely inherited by the craftsmen of this village.

\footnotetext{
${ }^{3}$ Water-Street is usually famous for its traditional buildings regularly arranged along the river.

4 Hong-Men-Liang is a building decoration for the traditional clan temple in Rucheng County of Hunan Province. For the traditional clan temples, Hong-Men-Liang is usually a decorated Great Lintel, installed on top of the main gate. Its main features include size, shape, hollowed-out work, and coloring style.
} 


\section{Connotation of CLGTS symbol mechanisms}

The natural languages are a kind of comprehensive symbolic expression systems. They have the special symbol systems and a wide range of socio-cultural constraints. They are treated as the basic media for humans to record, communicate and disseminate information. As mentioned above, Chinese traditional settlements are rich in CLGTS. For example, cultural landscape genes of traditional architectural heritage [56] often own special physical carriers or media, and can carry rich socio-cultural information, and express unique traditional cultural meanings, such as hollowed-out carving techniques, house shape, spatial layouts of settlements, spatial structures of settlements, establishing mode of building space, common places.

CLGTS is very similar to linguistic symbols. There are many ways to inherit CLGTS, not only including material appearances or carriers but also including restricted attributes, such as cultural connotation. This suggests that the features of CLGTS can be illustrated from the perspective of semiotics.

\section{Concept of symbolization method of CLGTS}

The Symbolization Method of CLGTS (SM-CLGTS) means constructing the symbol description model and associated graphic expression systems. It analyzes the traditional cultural connotation and deep features of CLGTS through referring to the relevant cartographic principles and methods. It can also support establishing and drawing the traditional settlement cultural genome maps for a given region [33]. From the viewpoint of semiotics, SM-CLGTS covers a wide range of topics, mainly including CLGTS analysis, definition of symbolic model, symbol taxonomy, and graphic-expression approaches. CLGTS can be considered as a symbol unit with sociohistorical and cultural information, and be described by especial methods [57]. This work is contributed to exploring the features of CLGTS symbols by modeling methods, symbol variables, and graphic representation principles of map symbols.

However, the clear differences between CLGTS symbols and map symbols should be explained in detail. In fact, they are reflected by the nature of CLGTS. The socio-cultural and socio-historical information are the most essential features and main constraints of CLGTS. In addition, CLGTS also includes important geo-environmental features and geo-spatial position information. Map symbols mainly represent geo-spatial position and geographical semantics of geographical objects/ phenomena.

SM-CLGTS deserves to be deeply explored because: (i) it is an important expansion of CLGTS theory from the perspective of linguistics and semiotics; (ii) it is helpful to rich the methods of CLGTS theory by referencing cartography; (iii) it can support drawing traditional settlement cultural genome maps for a given region; and (iv) for a given region, it can promote the protection of CLGTS by using digital technologies [58] and by carrying out corresponding resource surveys.

\section{Features of CLGTS symbol}

From semiotics, the following two distinct features of CLGTS symbol are clear.

First, with the support of symbols, the socio-cultural meanings and spatial attributes of CLGTS can be fully abstracted and effectively represented. By constructing a symbolic representation system, we can fully capture the nuances of different CLGTS with similar cultural connotation or physical appearances. This is because a symbol is a combination of pronunciation, form, as well as meanings, and it can be recognized or observed and recorded through its visual appearances. It is important to note that some principles and methods of map symbol design can also help people recognize the different CLGTS. For example, we can use the visual variables of map symbols [12] to recognize the similar CLGTS, such as color, texture, and shape.

Second, in the traditional settlement space, CLGTS is a combination of physical carriers with socio-cultural meanings (e.g. the spatial layout of traditional settlements) and traditional cultural information media with symbol significance. In other words, CLGTS is a combination of objectively existing entities and corresponding abstract symbolic meanings. CLGTS often has its own physical carriers or appearances. On the other hand, Chinese traditional settlements often endow CLGTS with certain cultural meanings and connotations or functions. This provides a theoretical basis for using the associated principles of map symbols to explore the features of CLGTS symbols. Each symbol of a natural language can correspond to an entity in the objective world because the language has established its own representation system. Similar to language symbols, each CLGTS can also correspond to a unique cultural factor of traditional settlements. This strongly suggests that there is a unique and objective correspondence between CLGTS and relevant cultural factors of traditional settlements. In fact, this correspondence can be clarified through mapping, generalization, and semantic constraint. Mapping means that CLGTS is a symbol-level semantic description, which mainly describes the corresponding physical carriers or physical existence. That is to say, mapping is to establish a strict correspondence between CLGTS and the related objective entity, which is of great significance to construct the visual representation model of CLGTS 


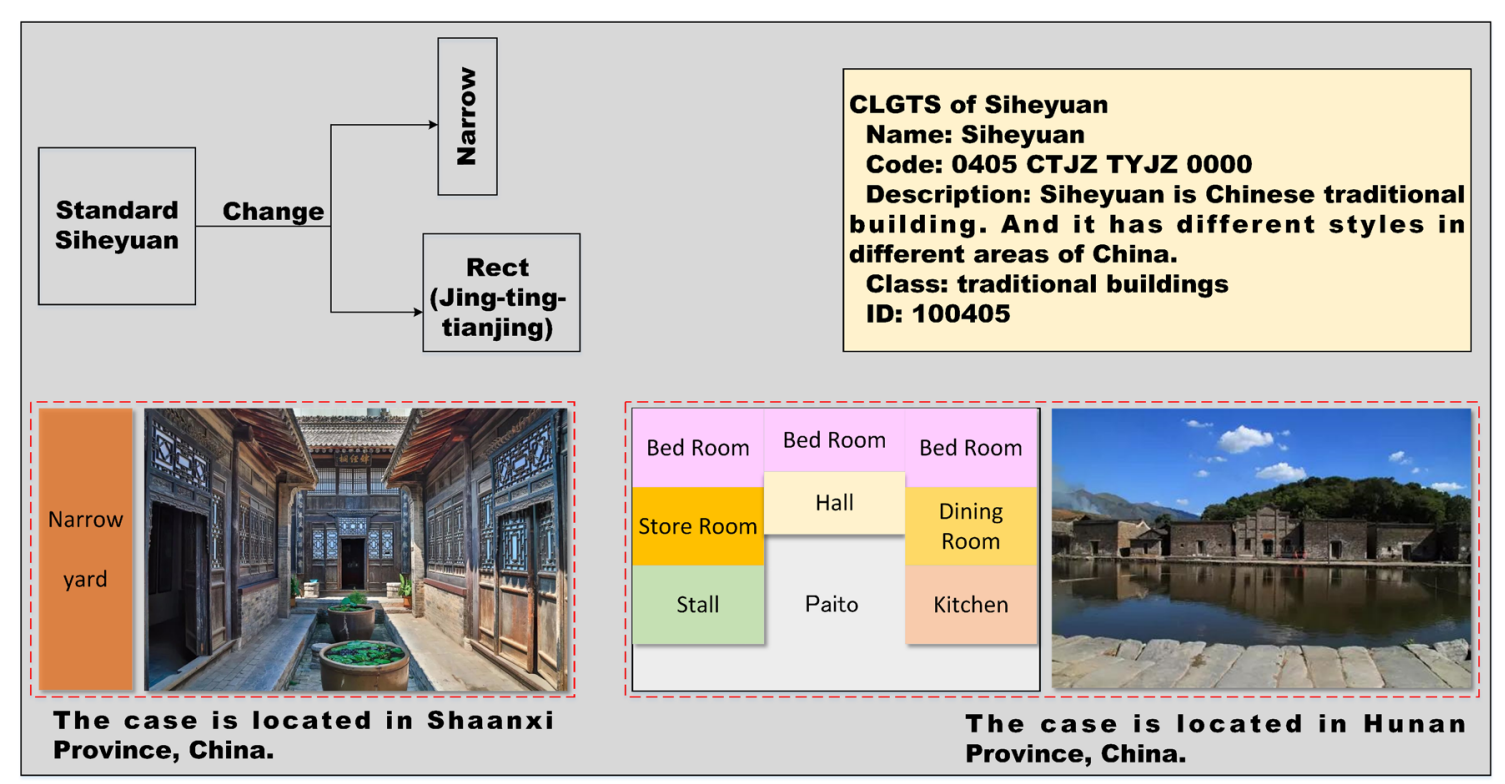

Fig. 3 CLGTS expression of traditional courtyard and its derivations by different variables

Table 1 A Classification for CLGTS symbols

\begin{tabular}{lll}
\hline Symbol class & Description & Note \\
\hline Graphic symbols & Using the graphic symbols composed of the basic elements to express the special meanings of CLGTS & Simple symbol \\
Picture symbols & Directly defining the pictures/images as the symbols to express some special meanings of CLGTS & Simple symbol \\
Texts symbols & Directly using text to describe the meanings of CLGTS & Textual symbol \\
$\begin{array}{l}\text { Spatial comprehen- } \\
\text { sive layout symbols }\end{array}$ & $\begin{array}{l}\text { Combining the mapping functions of GIS software to intuitively express the meanings of the layout } \\
\text { symbols of CLGTS }\end{array}$ & Compound symbol \\
\hline
\end{tabular}

symbols. Generalization implies that CLGTS symbols must conform to certain design principles, recognition laws of linguistics and semiotics. In fact, generalization highlights that the most distinguished and important features of CLGTS should be accurately represented from a semiotic perspective. Semantic constraint means the special information carried by CLGTS with traditional cultural meanings, such as history culture, and social ethics. We point out here that it should keep in line with the semantic constraint when using symbols to express the CLGTS. For example, we can use square to represent the traditional courtyard, and then combine other symbol variables to express other forms of courtyard-heritage, such as shape, color (Fig. 3). In Fig. 3, we use variable combinations to represent the different derivations of the traditional courtyard. Here, the variables include shape, size, and color. Shape and size can distinguish different derivations of the traditional courtyard and color can represent different functions of rooms in traditional courtyard.
From a semiotic perspective, CLGTS symbols can represent the peculiar cultural meanings of traditional settlements. We can employ the corresponding principles of semiotics to establish a visual representation model for CLGTS.

\section{CLGTS symbol classification}

An appropriate classification system can help us capture the essential features of CLGTS symbols. In this study, we mainly concern the visualization features when classifying the CLGTS symbols. In the fields of cartography, people often use graphics, texts, pictures, as well as images to figure and represent spatial information. This inspires us to classify the CLGTS symbols through bridging cartography. According to the cultural connotation of CLGTS and visual representation methods, CLGTS symbols can be divided into four types (Table 1): graphics, pictures, texts, and spatial comprehensive layouts.

Graphic symbols means that people can use a single graph or a collection of graphics to represent the core 
features and critical information of a certain CLGTS. For a given CLGTS, we can use a combination of basic graphic elements or specific patterns to represent its connotation or important attributes. For example, for the CLGTS of the Phoenix Ancient City, ${ }^{5}$ we can design a series of graphic symbols in the shape of Phoenix Divine Bird to describe it.

In fact, some CLGTS are difficult to be directly expressed with graphic symbols due to their complex forms, structures, appearances, and even complex associations with other CLGTS. Picture symbols hence refer to the use of pictures or images directly taken in the field investigations to represent them. For example, according to the field investigations in Rucheng County [55], we can directly use picture symbols to express the core cultural features of different styles which are used to decorate the clan temples of the ancient villages.

In addition, some CLGTS are still difficult to be expressed well through graphic symbols or picture symbols, such as non-material CLGTS, some cultural factors described or recorded by text, the cultural connotation of some specific cultural factors. For example, the Fiery Dragon is a popular traditional custom with rich cultural meanings in Rucheng County, which can not be directly described by graphic or picture symbols [55] because it is only held on the last day of traditional Spring Festival every year. For another example, Jiangyong Women Language $^{6}$ is directly recorded by special characters; it thus is very difficult for the public to learn and master because it is only used and disseminated by a certain group of women. It is worth stressing that the text symbols are the best option when the CLGTS is very difficult to be expressed through graphic symbols or picture symbols due to its existence circumstances or presentation conditions or recording approaches or complex connotation, such as the shape of Bai-shou-tang of Tujia Minority. ${ }^{7}$

It is important to stress that the spatial layouts of Chinese traditional settlements are an organic combination of traditional philosophy of ecology, traditional ecological wisdom, traditional knowledge of social development, and geo-environments. Traditional philosophy of ecology and ecological wisdom mainly include site selection and

\footnotetext{
${ }^{5}$ The Phoenix Ancient City is the capital city of Fenghuang County. It is located in Xiangxi Tujia \& Maio Autonomous Prefecture of Hunan Province. And the Phoenix Ancient City has well preserved a great amount of traditional buildings decorated by the Phoenix Divine Bird. According to Liu PL (2014), the Phoenix Divine Bird was identified as the CLGTS of Phoenix Ancient City.

${ }^{6}$ It also names as "Jiangyong Nü Shu". It is only popular among Yao Minority women in Jiangyong County of Hunan Province, and is recognized as the unique female language in the world.

${ }^{7}$ It is a great plaza for celebrating the traditional festivals with Hand-Waving-Dancing, usually located in the center of the Tujia Minority village.
}

settlement construction planning. Traditional knowledge of social development mainly includes survival wisdom, the relationship between man and environment, and social ethics. The spatial layout of a given traditional settlement is the center of entire features among design ideas, traditional cultures (e.g. ethics, religions, custom, etc.), and geo-environmental features. In order to express the auspicious meanings of the traditional geomancy, some Chinese traditional villages have designed the habitable spaces based on the surrounding natural conditions and geo-environment. Through the above, people can fully capture the traditional cultural meanings of spatial layout of traditional settlements from a holistic view. We can use maps to summarize the design features and related ideas or other core cultural features of traditional settlements, then further generalize the corresponding layout CLGTS. Because maps can show the entire features of spatial layouts of a given traditional settlement. In this study, for a given traditional settlement, we define its holistic feature map as the comprehensive spatial layout symbol. Because the holistic feature map of a given traditional settlement can effectively reflect its core features of the spatial layout through some key features, such as geo-environmental features, spatial design model, and layout characteristics. For example, Gaoyi Ancient Village (located in Huitong County, Hunan Province, China) is situated on the north bank of the Woshui River and is surrounded by mountains on three sides; note that, according to the Chinese traditional geomancy, this landform is similar to 'Taishi Chair' (one type of ancient armchair specially used for the nobles in ancient China); so, the spatial layout of Gaoyi Ancient Village is designed as 'Taishi Chair'; from a Fengshui perspective, it strongly hints that the descendants of this village will have a prosperous and powerful future.

\section{CLGTS symbol representation}

In practice, the cultural factors defined as CLGTS should meet the following conditions. First, CLGTS has outstanding traditional cultural characteristics, which can be distinguished from similar cultural factors in other traditional settlements. This hints that the recognizable features are the most important attribute of CLGTS. For example, for a Wa Minority traditional village, the totem pillar decorated with bull heads can be identified as its CLGTS [49]. Second, CLGTS has a strong sense of identification and recognition. To a certain degree, CLGTS can be regarded as an important cultural symbol of the spiritual space of traditional settlements [56], such as the Baishou-tang of Tujia Minority, the Gulou of Dong Minority (the highest, grandest, and most majestic traditional building in Dong Minority village). Third, CLGTS is very famous for the features of Chinese traditional philosophy, 
Table 2 Basic variables of CLGTS Symbols

\begin{tabular}{|c|c|c|c|}
\hline Variable & Description & Symbol example & Note \\
\hline Shape & $\begin{array}{l}\text { The shape characteristics of the material carriers or } \\
\text { indication objects of CLGTS }\end{array}$ & & The enclosure shapes of the house or yard \\
\hline Texture & The distribution characteristics of the regional CLGTS & & Some CLGTS can be distributed across regions or areas \\
\hline Size & $\begin{array}{l}\text { The size of the material carriers or indication objects } \\
\text { of CLGTS }\end{array}$ & & $\begin{array}{l}\text { The dimensions of houses, yards, primary common } \\
\text { buildings }\end{array}$ \\
\hline Pattern & $\begin{array}{l}\text { Some special patterns with the given traditional } \\
\text { cultural meanings of CLGTS }\end{array}$ & & $\begin{array}{l}\text { The decoration patterns are widely used in the tradi- } \\
\text { tional settlements }\end{array}$ \\
\hline Color & $\begin{array}{l}\text { Different colors can be used to distinguish the details } \\
\text { of the similar CLGTS }\end{array}$ & & $\begin{array}{l}\text { The traditional Siheyuan Buildings have many variations } \\
\text { in China }\end{array}$ \\
\hline Layout & $\begin{array}{l}\text { The whole spatial layout CLGTS of a given traditional } \\
\text { settlement is usually designed according to the geo- } \\
\text { environment conditions }\end{array}$ & 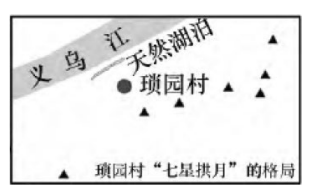 & $\begin{array}{l}\text { Suoyuan Ancient Village (located in the Yiwu City of } \\
\text { Zhejiang Province) is famous for the spatial layout } \\
\text { "Seven-Star-Around-Moon" }\end{array}$ \\
\hline
\end{tabular}

traditional social institutions, and traditional social ethics, such as the shapes and rules for constructing a gate of the clan temples. Fourth, the traditional cultural connotation of CLGTS can continuously remain its core features even after a long history of inheritance, such as the shape of Tulou, the enclosure features of traditional courtyard. It is clear that CLGTS is not only the generalization and abstraction of the important attributes of cultural factors of traditional settlement at the socio-ethical level but also the integration of the cultural connotation of traditional settlements at the symbol level, such as ancient social institutions, and ancient social ethics.

When examining a given CLGTS, in order to understand its traditional cultural features, we must not only think about itself but also analyze it in its original cultural eco-environments. This implies that the visual CLGTS symbols must have accurate definitions, simple composition, and intuitive representation models. It should be pointed out here that CLGTS can be considered as the smallest unit of historical and cultural information in the traditional settlement space. This hints that CLGTS has not only the attributes of spatial positions but also the rich traditional cultural information.

Despite CLGTS is only a conceptual description about the objective reality, it is still a logical framework established by generalizing or extracting the important attributes or features of objective real entities, such as shapes, textures, sizes, patterns, colors and layouts (Table 2). This shows that people can fully capture the outstanding features or attribute differences of CLGTS from the perspective of semiotics. For example, according to PL Liu and SS Dong [49], we can design a bull head shaped graphic symbol to express the totem CLGTS of Wa Minority (Wa Minority who is distributed in Yunan Province of China worships bulls. And there are often many bull-head shaped decorations in their campus/villages.).

Symbol variables and their corresponding combinations can highlight the differences among CLGTS in different regions or cultural backgrounds, such as shapes, colors, sizes, textures, patterns, as well as layouts. This suggests that we can effectively emphasize the socio-cultural meanings of CLGTS by scientifically using symbol variables. This is very helpful to improve the design quality of the corresponding CLGTS symbols. For example, the enclosure CLGTS of Tulou with different shapes can be distinguished by different symbols (Fig. 4): the square enclosure Tulou can be represented by the square symbol; the rectangular enclosure Tulou can be described by the rectangle symbol; the circular enclosure Tulou can be expressed by the circle symbol; the elliptical enclosure Tulou can be represented by the ellipse symbol. From Fig. 4, we can see that the detailed differences of enclosure CLGTS of Tulou can be described through symbols of different shapes.

\section{A prototype of CLGTS symbol application}

In practice, symbol application can be used to create or manage map symbols through referring to database principles or technologies. To a certain degree, symbolization is a special type of database applications. It uses the database technologies to centrally manage the map symbols that serve the specific application tasks. People usually establish different symbol applications to centrally manage map symbols according to the needs of geographic 


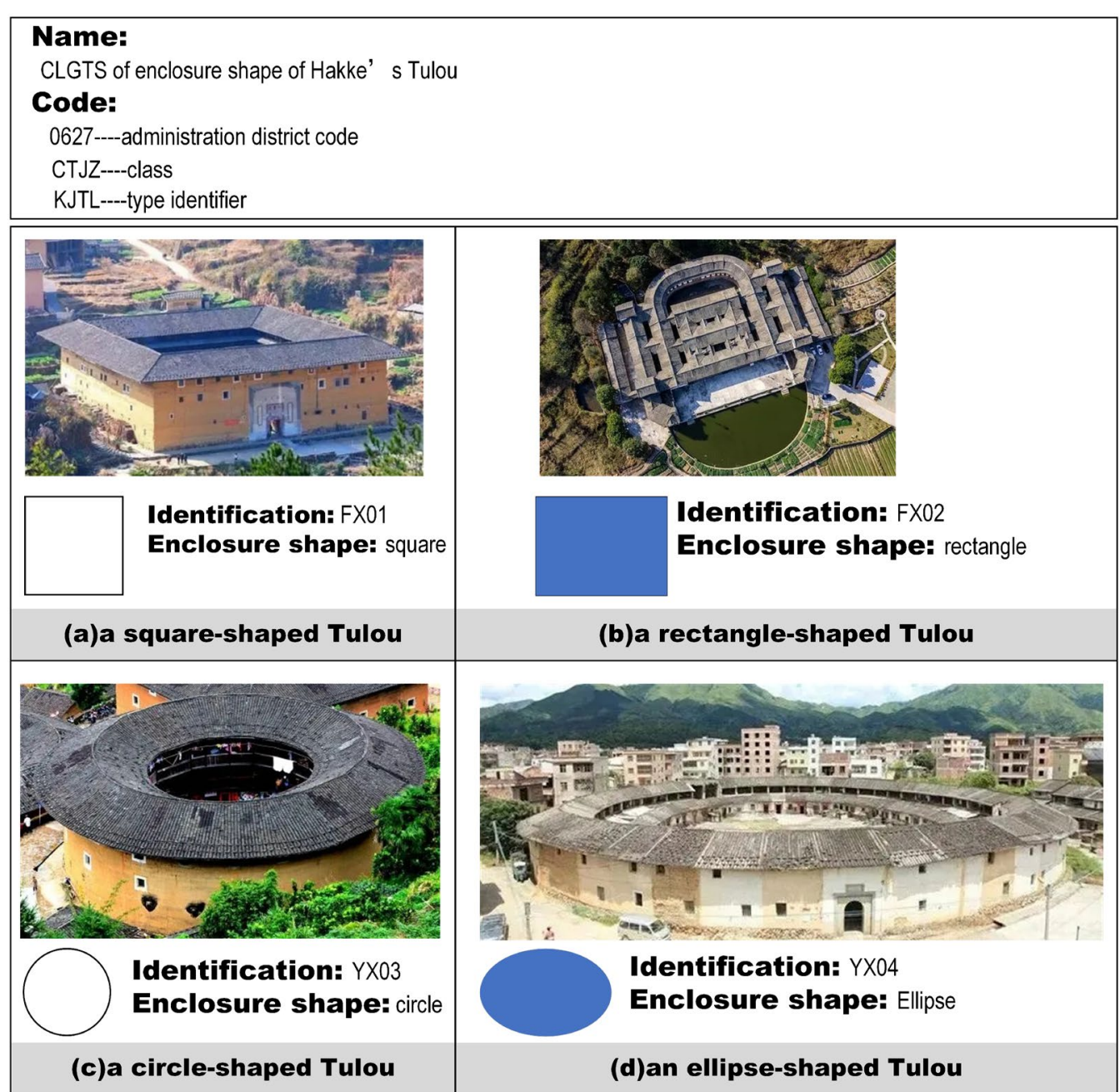

Fig. 4 A series of CLGTS symbols for different Tulou's enclosure: this example includes square, rectangular, elliptical, and circular enclosure shapes of Chinese Tulou. Here, we express the spatial enclosure shapes of different Tulou by combing different variables, including shape and color

information engineering tasks. The map symbols stored in the same symbol database share the same styles, norm or standards [25]. They are also consistent with the technical standards of national specifications for mapping and surveying. This work established a Traditional Landscape Genetic Symbol Database (TLGSD) for a given region through combing the above theoretical results with the ideas and methods of a map symbol application based on the semiotic approaches [59]. TLGSD is directly developed from the bottom level by using Visual C\#.net programming language.

In this study, TLGSD represents a potential way for visualizing CLGTS symbols. Simultaneously, TLGSD is of great significance of methodology and application to forward the symbolization method of CLGTS symbols. In TLGSD, we define an interface IGeneSymbol to represent the CLGTS symbols, and define an abstract class
CGeneElement to create and describe the CLGTS symbols. In addition, in terms of the classification of CLGTS symbols, we also define four classes through inheriting the abstract class CGeneElement: GraphGeneSymbol, ImageSymbol, TextSymbol, and ShpCompoundSymbol (Fig. 5). In Fig. 5, we also define an inherited class Draw according to the abstract class CGeneElement. Class Draw defines the basic graph elements, including Circle, Line, Polygon, Polyline, and Rect. In the other hand, all the basic graph classes are derived from Draw. Through Draw, TLGSD can create the basic graph elements and group them into a graphic symbol.

Some functions in ArcEngine Components have also been integrated into TLGSD (Fig. 6). TLGSD can create or maintain CLGTS symbols, and can also carry out some basic operations on CLGTS symbols, such as create, edit, modify, code, and save. 


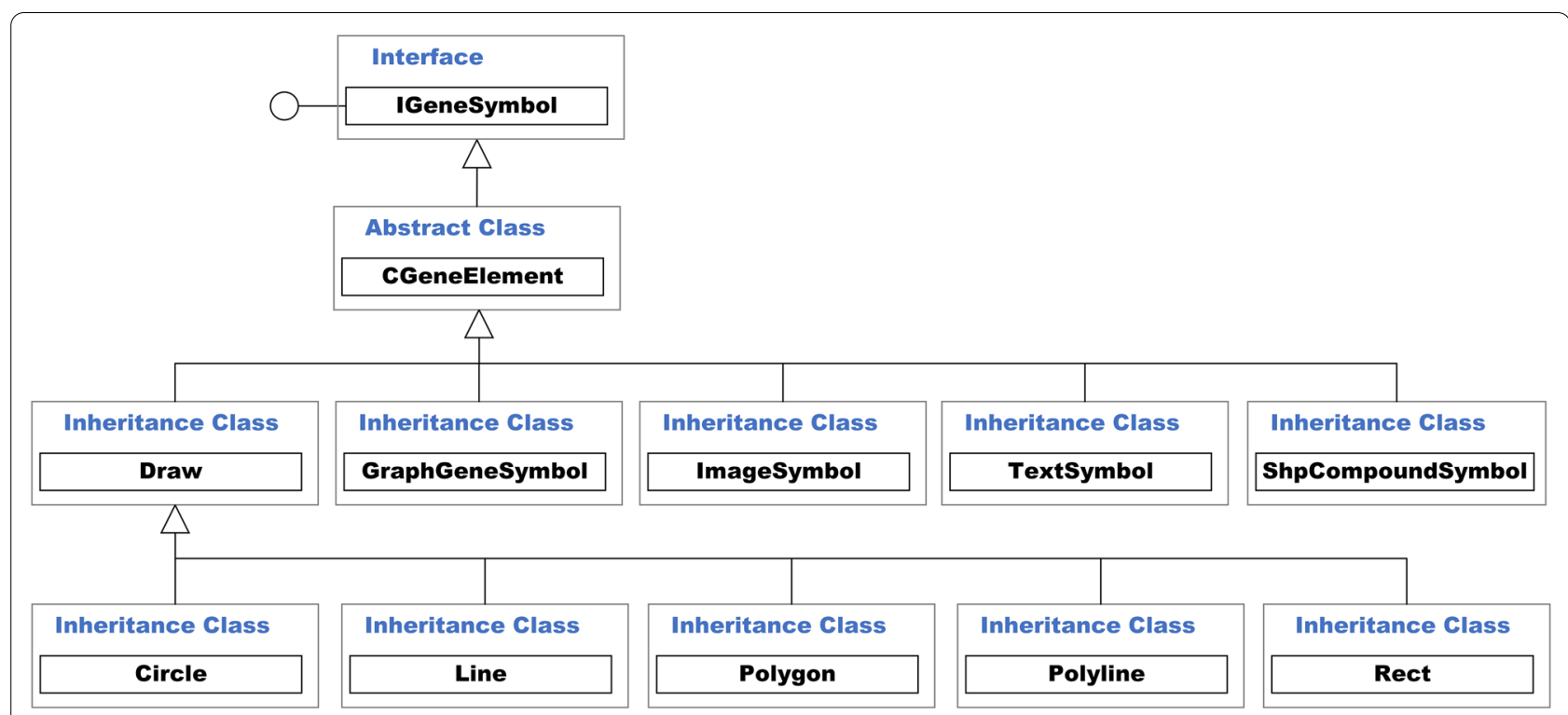

Fig. 5 Diagram of classes in TLGSD

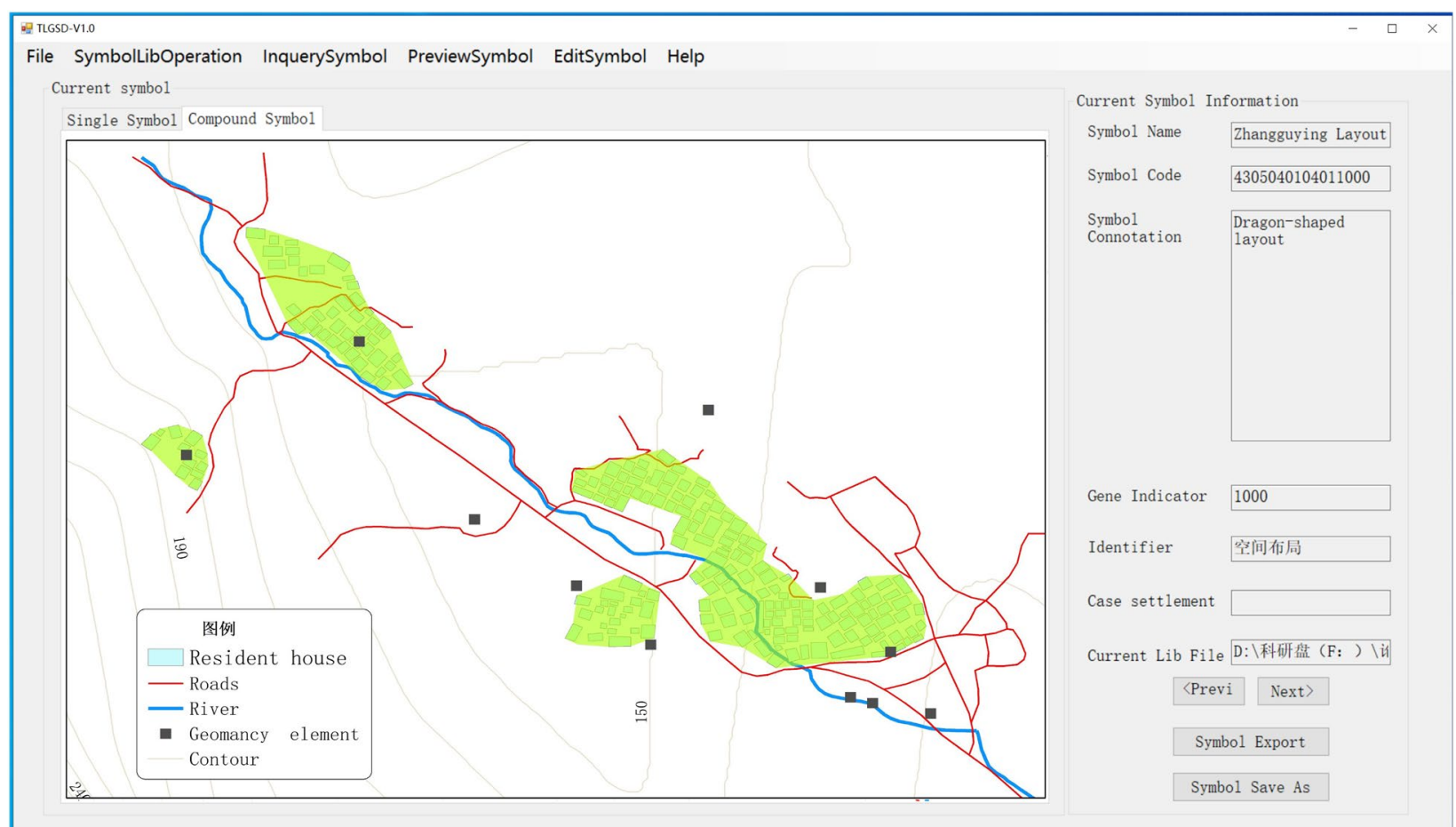

Fig. 6 The prototype system of TLGSD

TLGSD conforms to the principles and methods of object-oriented programming. In TLGSD, we use the critical attributes of CLGTS to construct the objects of CLGTS symbols, including symbol name, symbol class, symbol code (Fig. 7), and symbol meaning. Symbol name is a unique name for the corresponding CLGTS. Symbol class is the semiotic type of CLGTS symbols, including graphs, pictures, texts, and comprehensive spatial layout. Symbol code is a unique identifier for the corresponding CLGTS, which consists of 16 codes, including 


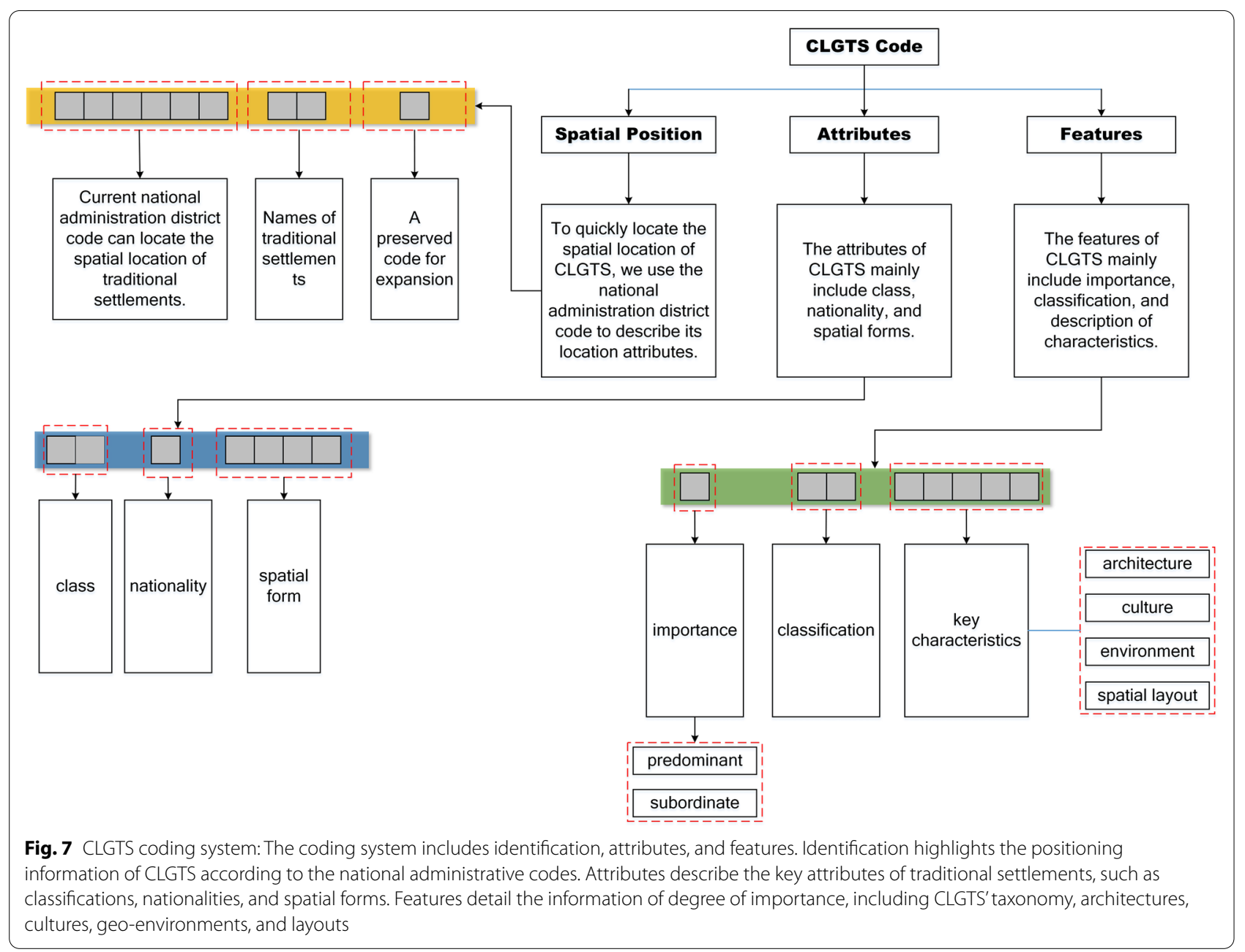

the characteristics of geo-spatial positions and cultural attributes. Symbol meaning is a unique variable which describes the socio-cultural meanings and features of CLGTS.

In addition, the attributes of CLGTS symbols in TLGSD also include feature descriptions and typical cases of traditional settlements. To help users create or maintain CLGTS symbols, TLGSD integrates all the attributes of CLGTS symbols into the same dialog (Fig. 8).

In TLGSD, the symbol editing is the core step of creating CLGTS symbols. In terms of the theoretical results, TLGSD defines CLGTS symbols as four functions: graph, picture, text, and compound (comprehensive spatial layout). Graph symbol function allows users to design or create CLGTS symbols through using the basic graphic elements well-defined in TLGSD. According to picture symbol function, the users can directly define picture CLGTS symbols through using the original pictures or the images obtained during the field investigations. If it is difficult for users to design graphs or use pictures/images while creating CLGTS symbols, text symbol function can directly define the feature description text of CLGTS as CLGTS symbols. Compound symbols are used to record the geo-environmental features and materials related to the spatial layouts of traditional settlements. Note that, for a given traditional settlement, users must study its spatial layout according to the geo-environmental features and the knowledge of Chinese traditional geomancy, such as landforms, watersheds, and rivers, etc. Maps can represent the core cultural features of the spatial layouts of traditional settlements. In order to help users make compound CLGTS symbols using the spatial layout map of traditional settlements, TLGSD can directly read the ".mxd" files of ArcGIS software through integrating ArcEngine Components.

In TLGSD, users can use the symbol variables to make CLGTS symbols. CLGTS symbol variables mainly include shape, texture, size, pattern, color, and layout (See Table 2). All these variables are integrated into the same dialog named symbol parameters. According to 


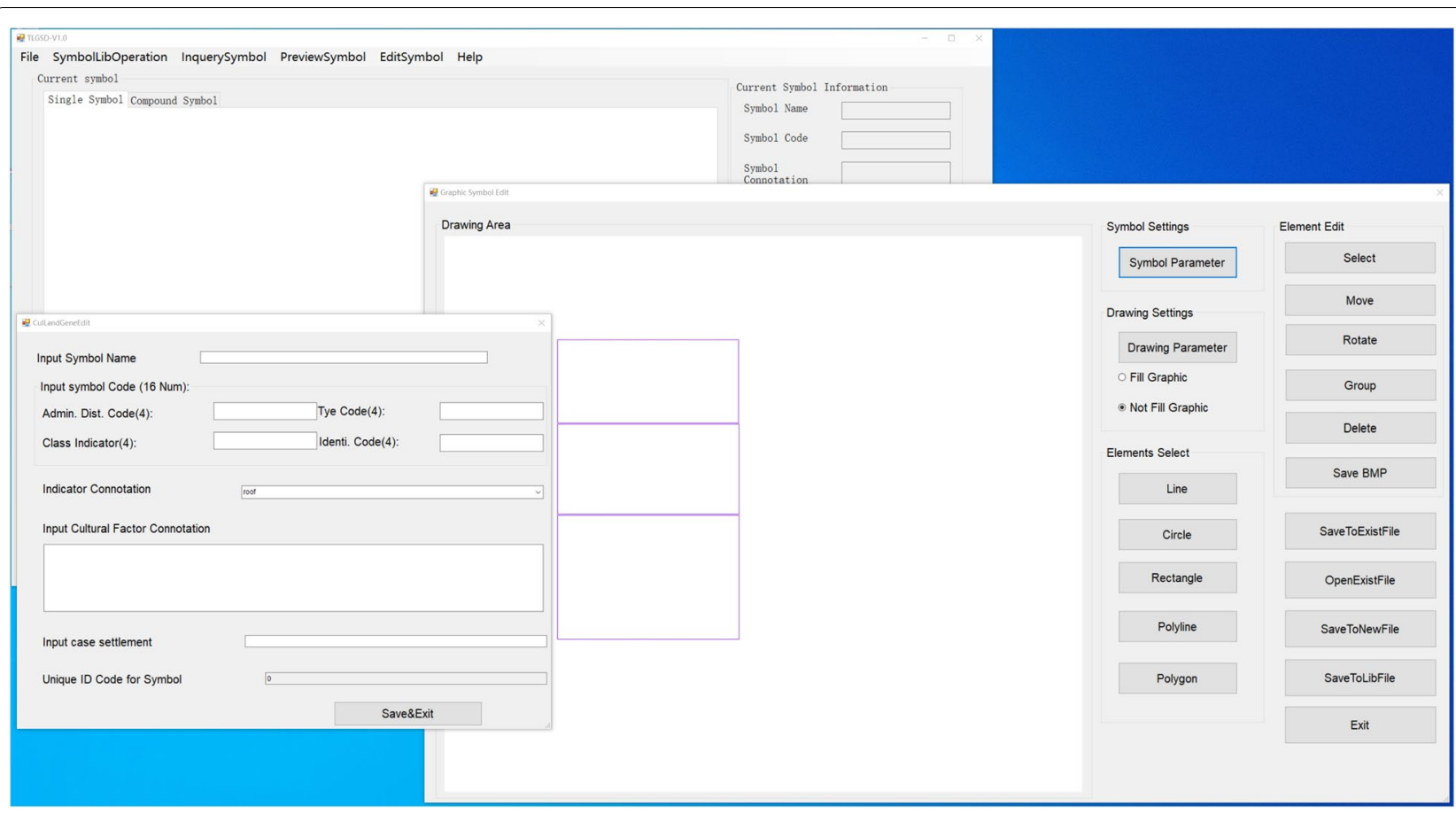

Fig. 8 CLGTS symbol edit functions in TLGSD

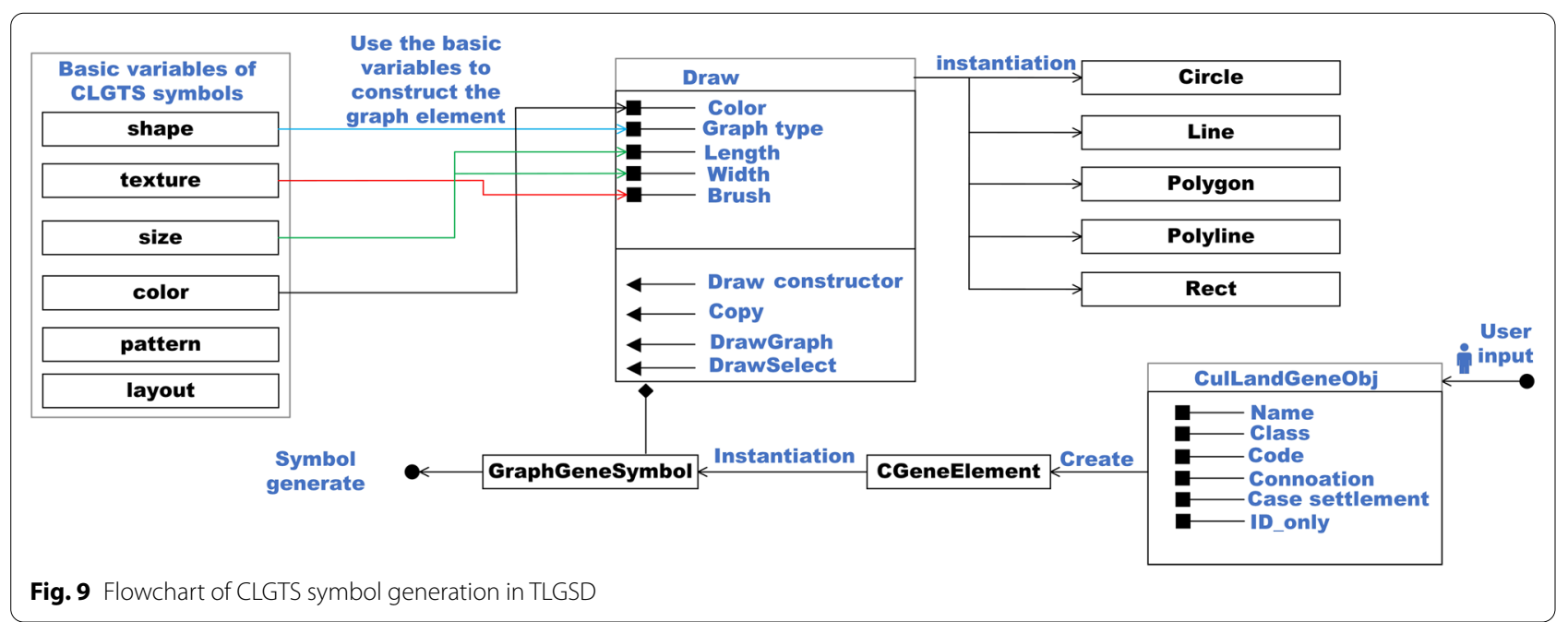

the corresponding requirements or application needs, users can use a single variable or a combination of different variables to make CLGTS symbols through symbol parameters. For example, in TLGSD, if we want to make a graph symbol, we should finish three steps (Fig. 9): to begin with, we should input the symbol parameters to create a CGeneElement object, including Name, Class, Code, Connotation, Case Settlement, and ID_only; furthermore, we can select the appropriate basic variable(s) of CLGTS symbols to finish the graph element settings and draw the corresponding graph elements; finally, we have to use the group button to build all the graph elements which we drew in previous steps into a graphic symbol.

Besides, the primary functions of TLGSD also include saving CLGTS symbols and query. The function of saving CLGTS symbols consists of a series of operations, mainly including connecting to database file, adding symbols to database, and updating database. Symbol inquiry function can help users look up CLGTS symbols that have 


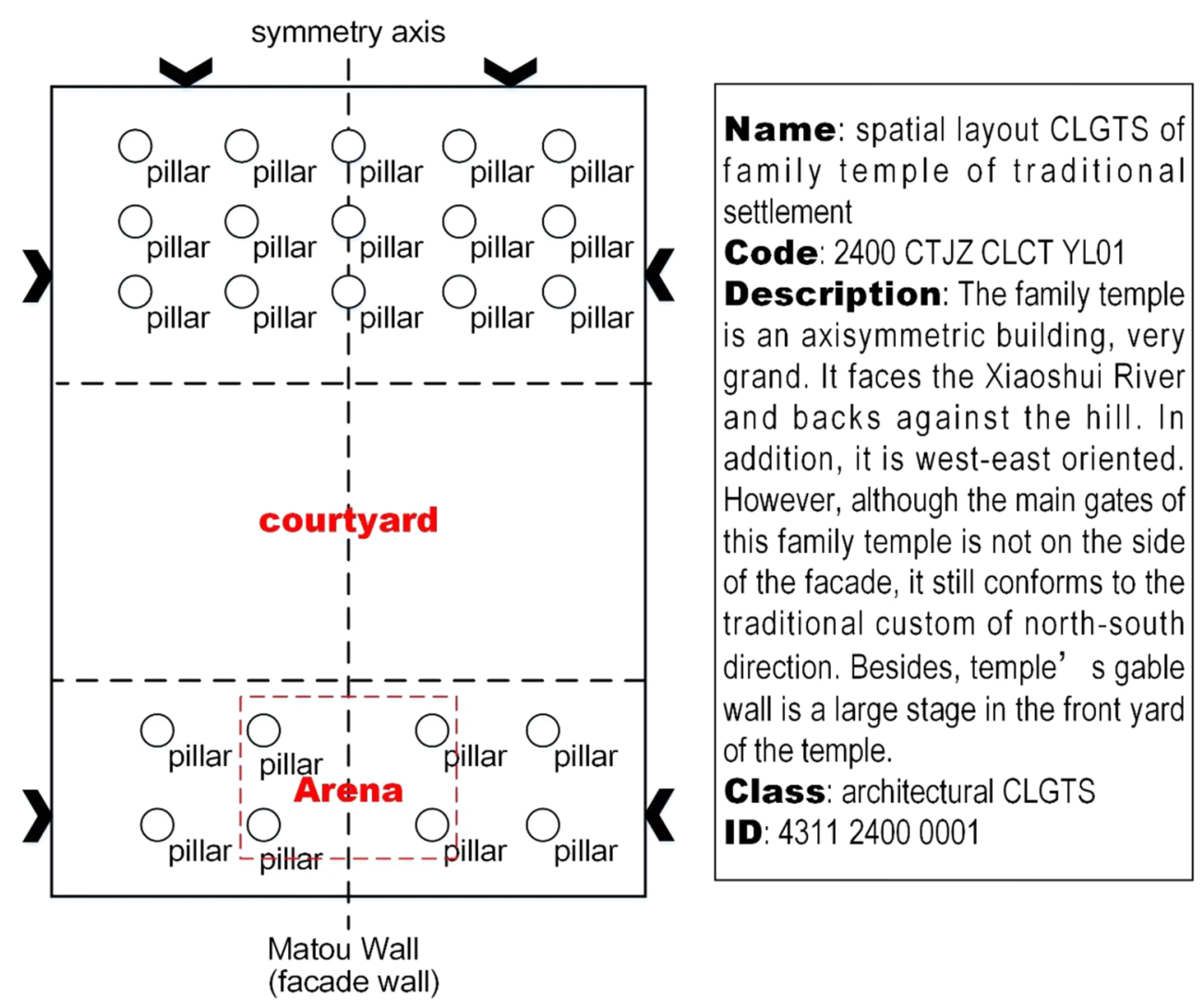

Fig. 10 An instance of CLGTS symbol: This instance of CLGTS symbol describes the main features of a family temple in an ancient village of one county located in Southern Hunan Province, China. This family temple is famous for its grand and majestic building, with an apparent axis of symmetry. The entire building of family temple is oriented east to west, which is clearly different from the general Chinese family temples oriented north to south. It is important to stress that the main gate of this family temple is opened to the south in order to keep in line with the Chinese traditional customs

been already saved in files. And this function can query the CLGTS symbols according to symbol name, symbol code, or typical cases of traditional settlements.

The test results of TLGSD prototype (Fig. 10) clearly show that it can meet the needs of establishing a CLGTS symbol database for a given region and can run well.

\section{Discussion}

Since CLGTS theory was put forward, it has focused on the understanding of the geographical features of the cultural landscapes of Chinese traditional settlements. However, in terms of the existing archives and reports, CLGTS theory does still lack of an effective approach to use visualization methods to capture the core features of the cultural elements or phenomena of traditional settlements in depth. Aim to solve this issue, we try to design and develop a definitional framework of visualization method of CLGTS by using the principles and methods of cartosemiotics.
From this study, we first constructed a theoretical model for visualizing CLGTS. We detailed this model through exploring the definition of symbolization method, features, classification, as well as the representation methods of CLGTS symbols. In order to examine this theoretical model, we developed a prototype procedure to make and centrally manage CLGTS symbols. From the test results, we can make clear that the prototype procedure can meet the needs of constructing a symbol database at regional scale. Obviously, this study is of great implications to forward the development of CLGTS theory from both theoretical research and application.

According to this work, visualization of CLGTS symbols is very promising in many application areas. For example, at the governmental level, the visualization method of CLGTS symbols can help people make policies to preserve traditional settlements and enhance cultural heritage. For another example, for a given region, people can also use the visualization method of CLGTS 
symbols introduced in this study to map or regionalize the spatial distribution patterns of the core cultural features of traditional settlements. At the same time, the industries engaged in the conservation of traditional settlements or sustainable development of tourism in traditional settlements can also benefit from this work. For example, the theoretical results and the possible applications can support the planning activities associated to the development of tourism in traditional settlements.

It is important to argue that the current research is still in its infancy when solving the issues in the application areas although we have developed a prototype procedure for making CLGTS symbols. Firstly, the prototype procedure should be further improved because the CLGTS symbols created by TLGSD in this study are still not available to any other GIS software. For example, although TLGSD integrates certain functions in ArcGIS software, the CLGTS symbols made by TLGSD are not visible and are not available to ArcGIS software. Secondly, the relationships between visual symbol variables and cultural landscape features of traditional settlements should be further developed and explored to promote the application of the visualization methods of CLGTS symbols. Finally, the coding system of CLGTS symbols introduced in this study needs further examination and improvement. In our current work, we only test the TLGSD with the present coding system of CLGTS symbols in a very limited region due to time and financial support. And this directly made us difficult to examine the adaptability of coding system of CLGTS symbols at a wider or nationwide scale.

In sum up, from this study, the urgent issue about visualization methods of CLGTS symbols is to develop a formal description model. Because a formal description model of CLGTS symbols can reveal the nature of relationships between semiotics and socio-cultural features of traditional settlements and enhance the availability of our visualization method for CLGTS symbols.

\section{Conclusions and outlooks}

CLGTS theory plays a significant role in the implementation of the social strategy of the great Chinese National Rejuvenation because it describes the core features of traditional settlements that are one of the most critical parts of Chinese excellent cultural heritage. This study presents a conceptual framework of SM-CLGTS and develops a prototype to create and centrally manage the corresponding CLGTS symbols by connecting the principles and methods of semiology and cartography.

Through this research, by elucidating the dialectical meanings, spatial shape, and structures of CLGTS, we can conclude that CLGTS is an abstraction and synthesis of the cultural collection of traditional settlements, which usually contains cultural institutions, social institutions, social ethics and traditional philosophies, etc. Note that each CLGTS has its own physical entities or objects in the traditional settlement spaces. This lays the theoretical foundation for making CLGTS symbols, and has a positive significance for improving CLGTS theory.

From this work, the conception and connotation of CLGTS symbols are first explored. CLGTS symbols are the findings of an in-depth analysis of the core cultural features of traditional settlements from a perspective of semiotics. They also can be considered as the visual graphic toolkit for analyzing the cultural connotation of traditional settlements. It therefore is of important meaning to promote the wide applications of CLGTS in further work.

According to the classification and expression methods of CLGTS symbols, and referencing the corresponding methods of map symbols, the work develops TLGSD prototype program for making CLGTS symbols. This is of crucial significance of providing a potential technical way for visualizing CLGTS symbols. The research has methodological significance for protecting the traditional settlements and corresponding cultural landscapes. On the other hand, government departments and policy makers who are serving the cultural heritage protection and sustainable development can also benefit from this study by introducing the visualization methods of CLGTS into their work.

Note that there are still some important issues which should be explored in depth. First, an appropriate formal description model of CLGTS symbols should be developed. It is very crucial to establish the design rules and a classification system for CLGTS symbols. Furthermore, there is still a lack of effective technical ways for making CLGTS symbols and forwarding their applications, e.g. integrating the TLGSD symbols into the mainstream GIS software. This will impact the digitalization of CLGTS. Through this study, the top priorities of the most important issues of CLGTS symbols include a formal description model, coding methods, symbol construction specifications, and symbol features.

\section{Abbreviations}

CLGTS: Cultural Landscape Gene of Traditional Settlements; TLGSD: Traditional Landscape Genetic Symbol Database; SM-CLGTS: Symbolization Method of CLGTS.

\section{Acknowledgements}

The authors are grateful to anonymous reviewers for their good suggestions for improving this paper.

\section{Authors' contributions}

ZH finished the whole research work, also designed and developed the prototype procedure abbreviated as "TLGSD" in this work, and wrote the manuscript. JS contributed his superb writing skills to this manuscript and corrected the errors. QM was in charge of the entire research thinking. MT was 
committed to improving the language of this manuscript. FC provided the funding support for this manuscript. All authors have read and approved the final manuscript.

\section{Funding}

The authors disclosed receipt the following support for the research, authorship, and/or publication of this article: this work was supported by the Natural Science Foundation of China [Grant number No.41771188], and the Hunan Provincial Foundation of Social Sciences [Grant number No.17ZDB050], and the National Key Foundation of Social Sciences [Grant number No.16ZDA159].

\section{Availability of data and materials}

Not applicable.

\section{Declarations}

\section{Competing interests}

The author(s) declared no potential interest with respect to the research, authorship, or publication of this article.

\section{Author details}

${ }^{1}$ Institute of Geographic Sciences and Natural Resources Research, Chinese Academy of Sciences, Beijing 100101, China. ${ }^{2}$ College of Geography and Tourism, Hengyang Normal University, Hengyang 421002, China. ${ }^{3}$ Department of Geo-Informatics, University of Salzburg, 5020 Salzburg, Austria. ${ }^{4}$ Aerospace Information Research Institute, Chinese Academy of Sciences, Beijing 100094, China.

Received: 20 March 2021 Accepted: 3 September 2021 Published online: 20 September 2021

\section{References}

1. Yu XR. Promoting agriculture green development to realize the great rejuvenation of the Chinese nation. Front Agric Sci Eng. 2020;7(1):112-3.

2. Wei WW. The art characteristics of Wangkou ancient village ancestral temple architecture. Int J Comput Eng. 2020;5(2):297-9.

3. Chen XH, Xie WZ, Li HB. The spatial evolution process, characteristics and driving factors of traditional villages from the perspective of the cultural ecosystem: a case study of Chengkan Village. Habitat Int. 2020. https:// doi.org/10.1016/j.habitatint.2020.102250.

4. Zhi MH, Yan ML. Digital protection and inheritance of ancient villages in southwest minority areas under the strategy of rural revitalization. Technol Forecast Soc Change. 2020. https://doi.org/10.1016/j.techfore. 2020.120238

5. Gou SQ, Li ZR, Zhao Q, Nik VM, Scartezzini JL. Climate respective strategies of traditional dwellings located in an ancient village in hot summer and cold winter region of China. Build Environ. 2015;86(4):151-65.

6. Sun S, Wang B. Low-altitude UAV 3D modeling technology in the application of ancient buildings protection situation assessment. Energy Procedia. 2018;153(10):320-4.

7. Wu WZ, Zhang LP, Qiu FD. Determinants of tourism ticket pricing for ancient villages and towns: case studies from Jiangsu, Zhejiang, Shanghai and Anhui provinces. Tour Manag. 2017;58(2):270-5.

8. Chen XW. The core of China's rural revitalization: exerting the functions of rural area. China Agric Econ Rev. 2019;12(1):1-13.

9. Chen MX, Liu WD, Lu DD, Chen H, Ye C. Progress of China's new-type urbanization construction since 2014: a preliminary assessment. Cities. 2018;78:180-93.

10. Chen MX, Ye C, Lu DD, Sui YW, Guo SS. Cognition and construction of the theoretical connotations of new urbanization with Chinese characteristics. J Geog Sci. 2019;29(10):1681-98.

11 Henning F, Mei KL. Affordances of narrative and numerical data: a socialsemiotic approach to data use. Stud Educ Evaluation. 2020. https://doi. org/10.1016/j.stueduc.2020.100846.

12. Bertin J. Semiology of graphics: diagrams, networks, maps, translated from French by W.J. Berg. Madison: University of Wisconsin Press; 1983.
13. Yao XF, Li B, Dong XQ, Wang JC. Integrated framework of wisdom manufacturing systems for semiotics perspective. Comput Integr Manuf Syst. 2014;20(11):2734-42 (In Chinese).

14 Yvonne D, Antonio P. Special issue on semiotics, human-computer interaction and end-user development. J Comput Lang. 2020. https://doi.org/ 10.1016/j.cola.2020.100948.

15. Johanna MS, Tuomo K, Jussi PPJ. Semantic distance as a critical factor in icon design for in-car infotainment systems. Appl Ergon. 2017;65(11):36981. https://doi.org/10.1016/j.apergo.2017.07.014.

16. Sauer CO. The morphology of landscape. Univ Calif Publ Geogr. 1925:2(2):19-54.

17 Whittlesey D. Sequent occupance. Ann Assoc Am Geogr. 1929;19(3):1625. https://doi.org/10.1080/00045602909357088.

18. Conzen MRG. Morphogenesis, morphological regions and secular human agency in the historic town space, as exemplified by Ludlow. In: Denecke $D$, Show $G$, editors. Urban historical geography: recent progress in Britain and Germany. Cambridge: Cambridge University Press; 1988. p. 255-61.

19. Gabriele F, Judith AV, Manley E. A computational approach to'The Image of the City.' Cities. 2019;89(6):14-25.

20. Wang D. Spaces in the spatial structures of traditional settlements. Peking: China Architecture and Building Press; 2016. (In Chinese).

21 Hu Z, Tang GA, Lü GN. A new geographical language: a perspective of GIS. J Geogr Sci. 2014;24(3):560-76.

22. Vladimír K, Jakub C. Analysis of large-scale maps symbols. Procedia Eng. 2015;111:450-3.

23. Anthony $C R$, Robert ER, Justine B, Scott P, Alan MM. A collaborative process for developing map symbol standards. Procedia Soc Behav Sci. 2011;21:93-102.

24. Schlichtmann H. Cartosemiotics. In: Bouissac P, editor. Semiotics encyclopedia online. Toronto: E.J. Pratt Library; Victoria University; 2008. p. 41-4.

25. Schlichtmann $\mathrm{H}$. Characteristic traits of the semiotic system "map symbolism." Cartogr J. 1985;22(1):23-30.

26 Sclichtman H. Plan information and its retrieval in map interpretation: the view from semiotics. In: Mark DM, Frank AU, editors. Cognitive and linguistic aspects of geographic space. Dordrecht: Kluwer; 1991.

27. Schlichtman H. On the semantic analysis of map symbolism: order by oppositions. In: Wolodtschenko A, Schlichtman H, editors. Diskussionsbeitrage zur kartosemiotik und zur Theorie der kartographie, 7. Dresden: Selbstverlag der Technischen Universitat Dresden; 2004. p. 20-34.

28. Schlichtmann H. Processes of sign production in map making. In: Kekelia J, Pravda J, editors. Map semiotics 1 (International map semiotic e-mail seminar). Tbilisi and Bratislava: INTELEQTI Publishers; 2006. p. 19-38.

29. MacEachren AM. How maps work: representation, visualization, and design. New york: Guilford Press; 1995.

30. Agnoletti M, Rotherham ID. Landscape and biocultural diversity. Biodivers Conserv. 2015;24:3155-65.

31. Li CJ, Li SS. Application of landscape gene information chain in tourism development of traditional human settlements: a case study of Daqitou Village in Sanshui District, Foshan City. J Landsc Res. 2017;9(2):42-6.

32. Xu J, Yao Y, Pei T, Yao C. Geographic knowledge map and its application in seismic knowledge representation. In: 2009 17th International Conference on Geoinformatics-Fairfax, va.IEEE: Newyork; 2009. p. 1-5.

33. Hu Z, Liu PL. The conceptual model and characterization of landscape genome maps of traditional settlements in China. Acta Geogr Sin. 2015;70(10):1592-605 (In Chinese).

34. Hu Z, Liu PL, Cao SQ. Spatial pattern of landscape genes in traditional settlements of Hunan Province. Acta Geogr Sin. 2013;68(2):219-31 (In Chinese).

35. Hu Z, Min QW, Liu PL. Identification on cultural landscape of traditional rice terraces in the southern area of China. Econ Geogr. 2018;38(2):80-7 (In Chinese)

36. Liu PL, Liu CL, Li BH, Deng YY, Shen XY, Hu Z. Characteristic and genesanalysis of traditional settlements' landscapes in Chinese Minority Areas. Sci Geogr Sin. 2010;30(6):810-7 (In Chinese).

37. Hu Z, Zheng WW, Liu PL, Liu XY. The forms and structures of traditional landscape genome maps: a case study of Hunan Province. Acta Geogr Sin. 2018;73(2):317-32 (In Chinese).

38. Richard D. The selfish gene. Oxford: Oxford University Press; 1976.

39. Constance M. Socio-cultural selection and the sculpting of the human genome: cultures' directional forces on evolution and development. New Ideas Psychol. 2013;31(3):390-406. 
40. Wilson EO. Sociobiology: the new synthesis (twenty-fifth anniversary edition). Cambridge: Harvard University Press; 2000.

41. Hu Z, Liu CL, Deng YY, Yang LG. Research progress on traditional settlements landscape's gene. Prog Geogr. 2012;31 (12):1620-7 (In Chinese).

42. Chen H. Analysis of landscape gene identification and its characteristics of traditional villages a case study of Zhuge Bagua Village. J Landsc Res. 2020;12(3):101-4.

43. Liu PL. The gene expression and the sight identification of the ancient villages' cultural landscape. J Hengyang Norm Univ. 2003;24(4):1-8 (In Chinese).

44. Liu PL. Traditional settlement cultural landscape gene: a precise interpretation for traditional settlement landscape gene's maps. Beijing: The Commercial Press; 2014. (In Chinese).

45. South AP, den Breems NY, Richa T, Nwagu U, Zhan TT, Poojan S, Outschoorn UM, Johson JM, Luginbuhl AJ, Curry JM. Mutation signature analysis identifies increased mutation caused by tobacco smoke associated DNA adducts in larynx squamous cell carcinoma compared with oral cavity and oropharynx. Sci Rep. 2019;9:19256-64. https://doi.org/10 1038/s41598-019-55352-y.

46. Liu PL, Liu CL, Deng YY, Shen XY, Hu Z, Li BH. Study on the identification of Hakka traditional village's landscape genes and analysis in the perspective of geography. Hum Geogr. 2009;24(6):40-3 (In Chinese).

47. Trevor JB. Quantitative Revolution. In: Kobayashi A, editor. International encyclopedia of human geography. 2nd ed. Amsterdam: Elsevier; 2020. p. 169-74.

48. Wang Y, Asterios A, Andrew C. Parametrising historical Chinese courtyarddwellings: an algorithmic design framework for the digital representation of Siheyuan iterations based on traditional design principles. Front Architectural Res. 2020;9:751-73.

49. Liu PL, Dong SS. Study on landscape-image of Chinese ancient village. Geogr Res. 1998;17(1):31-8 (In Chinese).

50. Hu L, Li Z, Liao WB. Fan Q Values of village fengshui forest patches in biodiversity conservation in the Pearl River Delta. China Biol Conserv. 2011;144(5):1553-9.
51. Liu PL, Liu CL, Deng YY, Shen XY. A study of icon-expression of China's ancient-city landscape genes "Cell-Chain-Shape" and regional differences. Human Geogr. 2011;26(1):94-9 (In Chinese).

52. Li X, Shang CC. An exploration of the cultural landscape model of Zhuge Village. Sustainability. 2018;10:3172-90.

53. Gao LH, Scott N, Ding PY. Attributes, theme, and value of a visit to Zhouzhuang, China. J Destin Mark Manag. 2016;5(3):239-48.

54. Fatiha L.'alim families in seventeenth-century and eighteenth-century Algiers: genealogy and heritage. Hist Fam. 2011;16(2):98-107.

55. Hu Z, Liu PL, Deng YY, Zheng WW, Qiu HH. Culture-gene identification of intangible cultural heritage for Rucheng County of China: a case study of Fiery Dragon. Hum Geogr. 2015;30(1):64 (In Chinese).

56. Zhu GY. China's architectural heritage conservation movement. Front Archit Res. 2012;1:10-22.

57. Hu Z, Liu PL, Deng YY, Zheng WW. A novel method for identifying and separating landscape genes from traditional settlements. Sci Geogr Sin. 2015;35(12):1518-24 (In Chinese)

58 Huang ZM, Liang YM. Digital protection and inheritance of ancient villages in southwest minority areas under the strategy of rural revitalization. Technol Forecast Soc Change. 2020. https://doi.org/10.1016/j.techf ore.2020.120238

59. Hu Z, Yan HW. Analysis on linguistics mechanism for cartographic symbols and its application. Geogr Geoinform Sci. 2008;24(1):17-20 (In Chinese).

\section{Publisher's Note}

Springer Nature remains neutral with regard to jurisdictional claims in published maps and institutional affiliations.

\section{Submit your manuscript to a SpringerOpen ${ }^{\circ}$ journal and benefit from:}

- Convenient online submission

- Rigorous peer review

- Open access: articles freely available online

- High visibility within the field

- Retaining the copyright to your article

Submit your next manuscript at $\boldsymbol{\nabla}$ springeropen.com 